\title{
Validation of the Newly Developed Graphical Inventory of Ethical Leadership (GIEL) Scale: Implications for Administrator Preparation and Business Leaders
}

\author{
Janet Hanson (Corresponding author) \\ Department of Educational Leadership, Azusa Pacific University (APU) \\ P.O. Box 7000, Rm 137, Azusa, CA 91702-7000, USA \\ Tel: 1-(626)-815-5375Ｅ-mail: jhason@apu.edu \\ William Loose \\ Department of Educational Leadership, Azusa Pacific University (APU) \\ P.O. Box 7000, Rm 136, Azusa, CA 91702-7000, USA \\ Tel: 1-(626)-387-5739Ｅ-mail: wloose@apu.edu \\ Ursula Reveles \\ Department of Educational Leadership, Azusa Pacific University (APU) \\ P.O. Box 7000, Rm 136, Azusa, CA 91702-7000, USA \\ Tel: 1-(626)-815-5426_E-mail: ureveles@apu.edu
}

George Hanshaw

Online Instructional Designer, Azusa Pacific University (APU)

680 Alosta, Azusa, CA 91702-7000, USA

Tel: 1-(626)-387-5886 E-mail: ghanshaw@apu.edu

Received: December 20, 2016 Accepted: January 22, 2017 Published: January 29, 2017

doi:10.5296/jei.v3i1.10480 URL: http://dx.doi.org/10.5296/jei.v3i1.10480 


\section{Abstract}

This quantitative pilot-study empirically tested the factor structure and reliability of the newly developed Graphical Inventory of Ethical Leadership (GIEL) scale, a Likert-style scale for quantifying key concepts related to ethical leadership. Correlations and principal components analyses were performed using pre-existing data as self-reports from a sample including 103 graduate students, within a Scholarship for Teaching and Learning project design, in an administrator preparation program at a private university located in a large southwestern state of the U.S. Face and content validity were demonstrated and empirical analyses revealed a three-factor structure for a unidimensional construct of ethical leadership. Internal reliability was above the pre-determined indices of Cronbach's alpha $>.60$ considered acceptable for scales in a pilot study. Potential uses of the GIEL include; as a baseline for setting and monitoring professional development goals, as evidence for recommending certification in administrator preparation programs, and as part of a 360-degree evaluation process.

Keywords: Ethical leadership, Survey validation, Administrator effectiveness

\section{Introduction}

The concept of virtue and integrity, as embodied in one's values and ethics, can be traced to Aristotle (1947). Virtue has been described as the foundation from which springs "the good life" and integrity as the foundation to ethical leadership. Ethics and integrity suggest a coordination between one's beliefs and actions, a wholeness and consistency that exemplifies moral behavior (Lawton \& Páez, 2014, p. 641).

\subsection{Influence of the Administrator on the Organization}

Leaders, managers, and administrators have positions of authority that wield considerable power and influence over the areas of distribution of resources and decision-making (Weber, 1947). To begin, a distinction exists between administrators, managers, and leaders. Organizations vary in form though most often provide a formal structure that defines roles and responsibilities in hierarchies of authority. Three roles of formal authority have been described by Boomer (2014) and include: leadership for vision and planning; management for execution and value creation; and administration to facilitate accomplishment of process and tasks (para. 1). The GIEL scale has been designed for use with all levels of hierarchical authority positions. In this paper, the term leader is interchangeable with all authority positions and used as the referent in the GIEL scale.

Formal and informal authority over decisions and resource distribution contributes to the development of power in the leaders' position and influence over others. However, leaders often experience negative influences from within themselves, as well as from others, while serving in their executive roles. Lord Emerich Edward Dahlberg Acton (2016) wrote an astute, and often quoted, description of the influence of authority on one's value base,

Power tends to corrupt and absolute power corrupts absolutely. Great men are almost always bad men, even when they exercise influence and not authority; still more when you superadd the tendency of the certainty of corruption by authority (para. 15). 
The abuse of power has long been viewed as a human trait, or behavioral tendency, throughout mankind's history and has been widely documented in many historical texts including the founding documents related to the history of the Colonies, the United States government, and the Bible. Included in the Federalist Papers is the statement,

In framing a government which is to be administered by men over men, the great difficulty lies in this: you must first enable the government to control the governed; and in the next place oblige it to control itself (Publius, 2016, para. 2).

Instead of ruling over others, Matthew 7:12 states, "In everything, therefore, treat people the same way you want them to treat you, for this is the Law and the Prophets."

\subsection{Description of the GIEL}

A variety of psychometric tools are currently available to measure attributes of leaders and constructs operationalized as factors of ethical leadership. The GIEL scale was designed in response to calls in the literature for improving the scale items and measurement method of ethical leadership in the workplace. The GIEL also responds to the call in the literature for using observed frequencies of behaviors as the measure, as opposed to followers' self-perceptions of leader's traits or characteristics (Lawton \& Páez, 2014; Yukl, Mahsud, Hassan, \& Prussia, 2013).

The method used to complete the GIEL scale includes obtaining responses on a Likert-style survey from both the leader and his reports, peers, and supervisors. Individuals complete the scale and sums are calculated for the leader, and a central tendency statistic for all reports, and others', responses is calculated to provide a 360-degree contextual view of the leader's ethical behaviors. This contrasts with other scales in the literature that quantify only followers' self-perceptions of the leader. Capturing the leader's context, through a 360-degree assessment, is critical in developing an understanding of existing perceptual differences between the leader and his or her followers, stakeholders, and/or supervisors.

Next, new methods for measurement and training, such as the use of technology and micro-learning strategies, must be developed and implemented to address the changing needs of the upcoming generation of organizational leaders, referred to in the literature as the millennials (Loose \& Marcos, 2015; Loose \& Marcos, 2016; Marcos \& Loose, 2014). This study describes a new scale being developed for use with micro-learning modules for professional development on the job.

The GIEL scale, developed and tested in this study, captures participants' self-reports, of observed behaviors of the leader, on 35 items related to seven key variables of an effective leader including; professional development, personal development, justice and fairness, communication, ethical decision-making, transformational leadership, and role model. A primary purpose of the 3D GIEL is to assist administrators in developing goals for growth, as a planning tool for practicing administrators, and for use in 360 evaluations. The GIEL survey results may be used as an artifact to demonstrate progress of managers in industry, as well as educational leaders in schools, toward understanding the competencies demonstrated by ethical leadership behaviors. 
1.3 Use of the Scholarship for Teaching and Learning (SoTL) Design

Discussions held by the educational leadership master's department team evolved from the need to provide a means for students in the administrator preparation programs to examine ethical and moral aspects of school leadership, as required in Standard 5 of the California Commission on Teacher Credentialing California Professional Standards for Educational Leaders (CPSEL). The development of the GIEL, and testing of the construct validity, has been explored through the use of a Scholarship for Teaching and Learning Design (SoTL) design described as follows:

The Scholarship of Teaching and Learning (SoTL) uses discovery, reflection, and evidence-based methods to research effective teaching and student learning. These findings are peer reviewed and publicly disseminated in an ongoing cycle of systematic inquiry into classroom practices. This work benefits students and colleagues and is a source of personal renewal (CSU, 2015, para. 1).

Students use the GIEL, develop goals, create tasks, and reflect and inquire at their work sites on their ethical practices. Anonymous and confidential data from the students' surveys were used to empirically test the reliability of the GIEL and identify the factor structure.

\subsubsection{California Professional Standards for Educational Leaders (CPSEL)}

In the mid 1990's, the Interstate School Leaders Licensure Consortium (ISLLC), composed of a variety of national stakeholder groups, was assembled and charged with the task of designing the first set of national standards for educational leaders. In 2001, California adopted the standards and formally adopted the first set of California Professional Standards for Educational Leaders (CPSEL). In 2004, the CPSEL were adopted as part of the standards-based program for the Administrative Services Clear Credential. In February 2014, a revised set of CPSEL were approved by the Commission. After reviewing the original CPSEL, research studies, professional literature, examples of national, state and district standards for administrators, as well as the newly adopted content and performance expectations for preliminary administrator certification, the CPSEL Update Panel drafted the updated set of CPSEL. Figure 1 shows the model of CPSEL Standards: core expectations for administrators. 


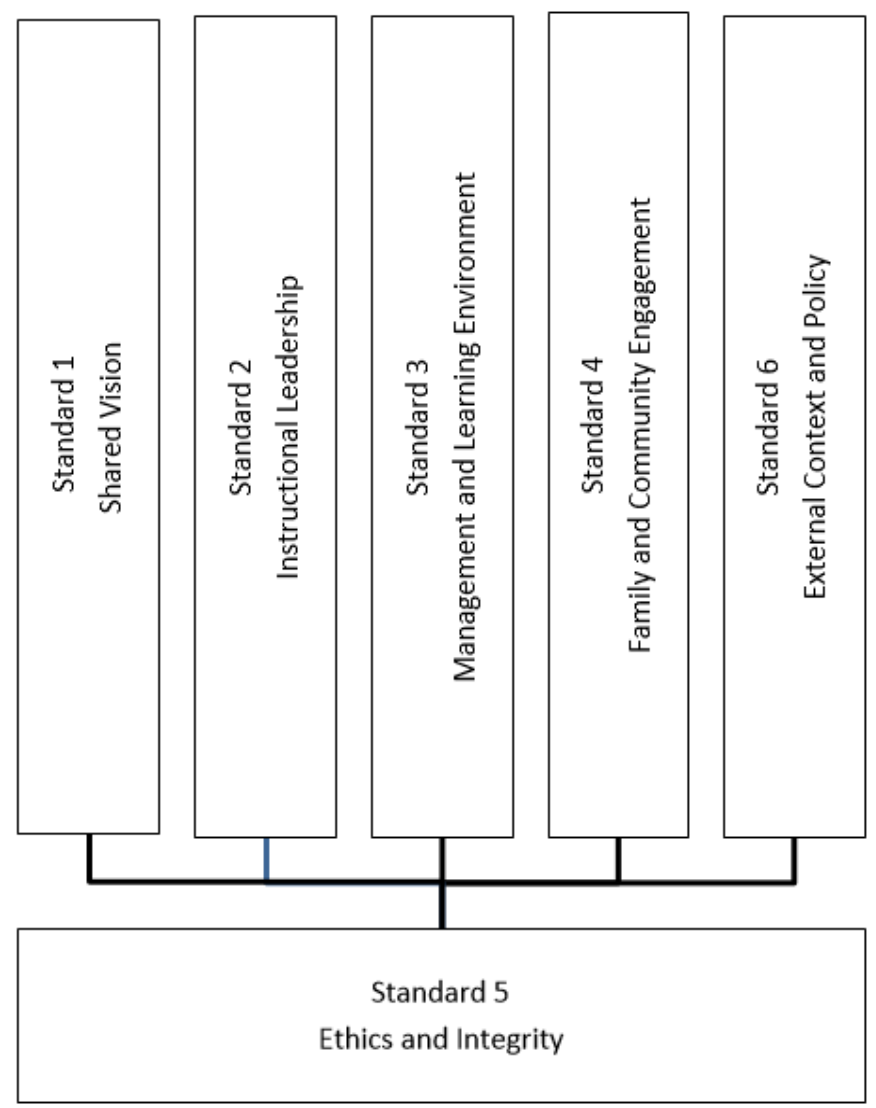

Figure 1. Model of CPSEL Standards: core expectations for administrators (CCTC, 2014)

The Master's department program team performing this study conceptualized Standard 5: Ethics and Integrity as the base from which the administrator's behaviors, choices, and decisions are influenced.

\subsubsection{CPSEL Standard 5: Ethics and Integrity}

California Professional Standard for Educational Leaders states, "Education leaders make decisions, model, and behave in ways that demonstrate professionalism, ethics, integrity, justice, and equity and hold staff to the same standard" (CTCC, 2014, p. 9). Efforts to ensure an educational leader evidences the standard's expectations requires the candidate's continuous reflection on her personal standards and values, a commitment to continuous professional and personal growth, and a plan to execute strategies to improve. The CCTC Standard 5 describes behaviors of ethical leaders including:

... the use of relevant evidence and available research to make fair and ethical decisions to guide personal and collective actions in the school, using their professional influence to support a trusting school climate resulting from mutual respect and honest communication. Equity and justice in operations and decisions related to staff and students provide a model for others' actions (CCTC, 2014, p. 9-10). 


\subsection{Purpose Statement}

This paper proposes to test the factor structure, reliability, and construct validity of the new GIEL scale quantifying leaders' behaviors as found in the literature under the description of ethical leadership (Brown, Treviño, \& Harrison, 2005, in Lawton \& Páez, 2014, p. 641). Understanding the ethical leadership concept in context is necessary to developing transformational leaders, who can contribute to successful organizational outcomes. Historically, assessment measures in the area of ethical leadership have largely focused on traits, or characteristics, of the leader as followers' perception quantified on a scale. This current research seeks to provide evidence that the GIEL scale, which uses leaders' behaviors and self-reports from a variety of sources, is a reliable instrument for collecting data from which valid conclusions can be drawn in the area of leaders' ethical leadership behaviors.

\subsection{Problem Statement}

The GIEL instrument is currently used by administrator candidates in the educational leadership program at a private university in a large southwestern state of the United States. Students complete the survey about their behaviors and receive 360-degree feedback, then develop personal and professional goals for their program term. The students retake the survey at the end of the program and use their progress as an artifact to evidence growth in ethical leadership behaviors, as required under CPSEL 5: Ethics and Integrity.

The GIEL instrument had not undergone empirical testing to provide evidence in support of its purported factors and scale reliability. Not understanding the underlying factors purported to be quantified on the GIEL instrument may lead to misinterpretation of a candidate's skills and to faulty conclusions about his or her progress. For those using the CPSEL to understand and evaluate a candidate's growth and competencies in meeting CCTC standards, valid measurement tools are necessary to accurately judge progress.

Candidates may not fully understand the expectations of the Standards without clear constructs on reliable scales to determine a measurable level of attainment of the expectations. Therefore, the development of an instrument for quantifying administrator behaviors as factors of Standard 5: Ethics and Integrity is warranted. Similarly, executives and managers in industry would benefit from a reliable scale to quantify the construct of ethical leadership in the workplace.

\subsection{Research Questions}

The overarching research questions for this study included:

Is there a relationship between the individual factors included on the Graphical Inventory of Ethical Leadership (GIEL) survey instrument?

Are the scale reliability indices of the GIEL instrument within predetermined acceptable parameters?

A history of the development of the ethical leadership theory and implications from the results of this study will be provided as a primer for educational leadership departments and 
industry administrators to develop an understanding of how ethical leadership theory fits into transformational leadership practices in schools and industry. Practical interventions for supporting student learning and a summary and conclusion of the results will also be provided, discussing the importance of understanding the use of ethical leadership factors in the social context of the workplace. Following are a list of definitions of terms used on the GIEL scale and in this paper.

\subsection{Definition of Terms}

360-degree evaluation process: The GIEL process includes feedback to the leader, usually anonymous and confidential, from his or her peers, supervisors, and reports for the purpose of developing goals for professional development, accountability, and providing data-based evidence to begin dialogues for addressing concerns.

Professional development: Professional learning to be up-to-date with education research, literature, best practices, and trends to strengthen ability to lead (CCTC, Standard 5A-3, 2014).

Personal development: One's conscious effort of using self-reflection and inquiry to promote the recognition and correction of biases and errors in one's beliefs, understandings, and values. The act of promoting one's interpersonal relationships and abilities to engage and promote the mutual benefit and welfare of self and others.

Justice and fairness are often used interchangeably though in this paper Rawls (1985) definitions will frame the discussion. Justice contains the concepts of moral values that support principles of liberty and equality for the group members. Fairness consists of creating equal opportunity, which may require permitting inequalities that create advantages for those underserved; that is, recognizing the needs of diverse populations.

Effective communication occurs through a process of active listening, positive affect, trust, relationship-building, and the ability to engage others. Effective communication results in the creation of mutual understandings and may be accomplished using a variety of mediums such as verbal, non-verbal, technological, written and visual media, and networking.

Ethical decision-making involves the consideration and evaluation of the potential moral and legal consequences of decisions. This includes the review of multiple measures of data and research on effective teaching and learning, leadership, management practices, equity, and other pertinent areas to inform decision-making. This also pertains to the leader's identification of personal and institutional biases and their efforts to remove barriers that derive from economic, social-emotional, racial, linguistic, cultural, physical, gender-based, or other sources of educational disadvantage or discrimination (Kearney, 2015, p. 34).

Ethical leadership: was described as consisting of “... the demonstration of normatively appropriate conduct through personal actions and interpersonal relationships, and the promotion of such conduct to followers, through two-way communication, reinforcement, and decision-making" (Brown, Treviño, \& Harrison, 2005, in Lawton \& Páez, 2014, p. 641).

Transformational leadership: Transformational leaders elicit social norms to raise others to 
higher moralities and motivation for causes that are valuable to the individual participants (Kouzes \& Posner, 2007, p. 22).

Role model: Encourage and inspire others to higher levels of performance, commitment, and motivation by modeling transparent and accountable behavior (Kearney, 2015, p. 36).

Organizational citizenship behavior: Behavior that contributes indirectly to the organization through the maintenance of the organization's social system (LePine, Hanson, Borman, \& Motowidlo, 2000; Motowidlo, Borman, \& Schmit, 1997; Motowidlo \& Schmit, 1999; Organ \& Ryan, 1995).

Rater Bias: "Rater errors are errors in judgment that occur in a systematic manner when an individual observes and evaluates another. Personal perceptions and biases may influence how we evaluate an individual's performance. What makes these errors so difficult to correct is that the observer is usually unaware that she or he is making them" (Trustees of Dartmouth College, 2016, para. 1).

\section{Literature Review}

Ethical leadership has been widely researched and discussed in peer-reviewed literature. The leader's followers make judgments about a leader's attributes based upon the leader's behaviors. A school leader's personal values and ethics have been shown to influence a leader's decisions and actions; to directly impact a school faculty's perceptions; and to positively influence the school culture. The organization's culture has been shown to be a significant variable influencing individual choices for behaviors that contribute to the improvement of organizations (Brown, Treviño, \& Harrison, 2005, p. 120; Lawton \& Páez, 2014; Reed, Vidaver-Cohen, \& Colwell, 2011; Tarter \& Hoy, 2004; Marzano, Waters, \& McNulty, 2005; Sergiovanni, 2009; Yukl et al., 2013).

\subsection{Construct Validity of Ethical Leadership}

Ethical leadership has been quantified, explored, and reported in the literature as both a unidimensional and multidimensional construct. Lawton and Páez suggested a model of three overlapping circles for their research study framework of ethical leadership. The three factors in their model included leadership practices, purposes, and virtues. Researchers are currently exploring meta-theories of organizational purpose based upon virtue theory including recognition of the common good and ethical leadership (p. 645). Ethical leadership has been show to explain outcomes such as trust, organizational citizenship behavior, and employee effectiveness (Kalshoven, Den Hartog, \& De Hoogh, 2011). This is consistent with Tarter and Hoy (2004) in their enabling school structures influenced by the ethical behaviors of the administrator. The Ethical Leadership Scale factor of interpersonal support compared favorably with the concept of Organizational Citizenship Behavior as well (Reed et al., 2011).

\subsection{Scales for Measuring Ethical Leadership Constructs}

This section provides a discussion comparing and contrasting a variety of ethical leadership constructs operationalized on scales found in the literature. The scales discussed include: the Ethical Leadership Scale (ELS), Ethical Leadership at Work Scale (ELW), Executive Servant 
Leadership (ESLS) Factor Scale, Ethical Leadership Questionnaire (ELQ), and a three dimensional framework for understanding and designing research on ethical leadership. A map of the constructs is provided and the items, dimensions, scales used, unit of data collection, and concepts used in correlational studies are provided. Figure 2 shows the map of comparable and contrasting concepts with ethical leadership constructs.
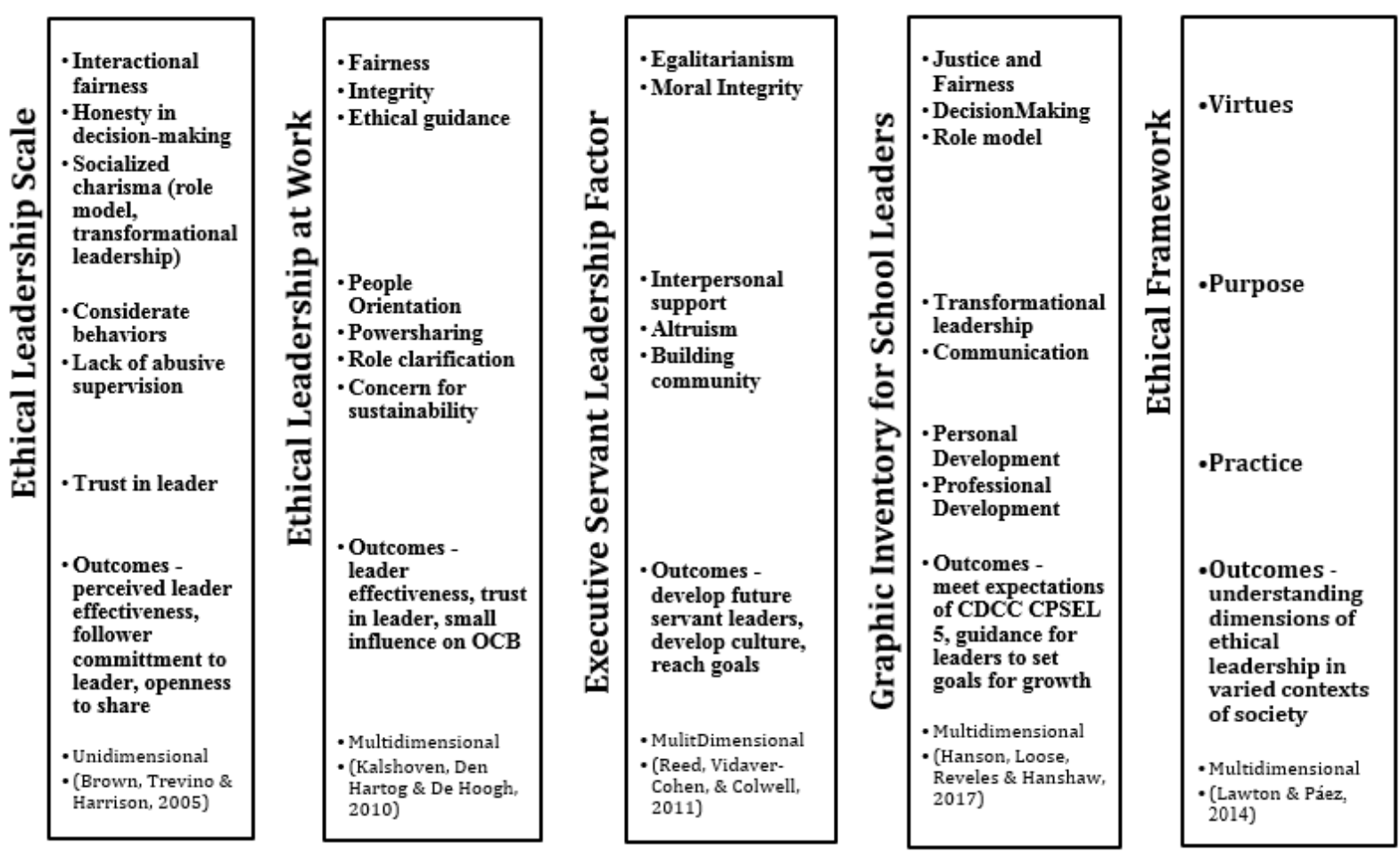

\section{Unit of Data Collection}

Followers

Followers

Followers

Leader, followers, others

The Literature

Figure 2. Map of comparable and contrasting concepts with ethical leadership constructs

Lawton and Páez (2014) developed and suggested a framework for research on ethical leadership including three dimensions: virtues, purposes, and practice. Their research described the importance of considering the context in which the leader practices leadership ethics and behaviors. They suggested the appropriateness of values and roles differ under different contexts and the leader must be aware of these culture and norms of the followers. Their focus on activities of the leader is consistent with the decision to operationalize the constructs on the 3D GIEL as leadership behaviors rather than traits. The move away from a trait-based perspective of values and ethics reflects the broadening perspective that recognizes the influence of cultural, political, and social norms as unique in each context ( $p$. 645). This framework provided by Lawton and Páez is consistent with the Hofstede and GLOBE Models (Global Leadership and Organizational Behavior Effectiveness) exploring 
culturally dependent views of effective leadership (Shi \& Wang, 2011).

Brown et al. (2005) developed and validated the Ethical Leadership Scale (ELS). This 10-item unidimensional scale operationalizes six constructs: consideration behaviors, honesty, trust in the leader, interactional fairness, socialized charisma (related to transformational leadership, role model, high standards, and cognitive moral development), and abusive supervision. The scale is completed by the followers of the subject leader. Brown used the framework of social learning theory (Bandura, 1986), to conceptualize a leader as a role model whose ethical conduct influences the same behaviors in his or her followers (p. 119).

Kalshoven et al. (2011) developed their Ethical Leadership at Work Scale (ELW) as a multidimensional construct including seven dimensions: fairness, integrity, ethical guidance, people orientation, power sharing, role clarification, and concern for sustainability. Subjects are employees or followers and self-reports of their perceptions are captured on Likert-style scale of $1=$ strongly disagree to $5=$ strongly agree. Correlation studies with the ELW revealed positive relationships with employee trust in their leader, job and leader satisfaction, organizational and team commitment, employee effectiveness, and organizational citizenship behaviors. A negative correlation was found with employee cynicism.

Reed et al. (2011) provided a description of their validated instrument and empirical studies for the Executive Servant Leadership (ESLS) Scale including five dimensions: interpersonal support, building community, altruism, egalitarianism, and moral integrity. The scale was provided to adult learners and alumni from a university. The participants were asked to rate their level of agreement on items describing the top executive in their institution on a 4-point Likert-style scale from 1 = strongly disagree to $4=$ strongly agree. Reed et al. framed their scale on the theory of trust as a foundation of ethical leadership. Trust supports a cohesive integration of activities, cooperation, and perception of stability. This concept is consistent with the Open Systems theory of collective efficacy and consistent with Bandura's (1986, 2001) descriptions of trust as a necessary antecedent to collective efficacy.

Yukl, Mahsud, Hassan and Prussia (2013) reviewed several of the previously listed scales and developed a 15-item unidimensional scale titled the Ethical Leadership Questionnaire (ELQ) from a review of several of the existing ethical leadership scales. They found that some leadership scales included constructs that were not "inherently ethical, and ... can be used for unethical purposes" (p. 40). Therefore they omitted constructs related to leader's behaviors of wider social issues, such as the issue of sustainability. The ELQ also excluded items related to personality traits, cognitive skills, a leader's openness to new information, and connecting ethical leadership constructs with unit outcomes; suggesting these constructs can be used either ethically or unethically. For example, some unethical leadership behaviorsinclude cheating or misrepresenting student results on accountability reports that may appear to improve unit performance in the short run.

The authors of the ELQ explained that excluding items related to these three constructs avoids confounding the results that overlap with other constructs in ethical leadership scales. Correlation and regression results in their study revealed these confounding variables accounted for $52 \%$ of the EL construct. The domain of ELQ includes a leader's values and 
behaviors reflecting the construct of integrity between espoused values and actual values in use: setting clear standards, holding others accountable, fair distribution of rewards, and transparency.

\subsection{Framework for Understanding the Measurement of Ethical Leadership}

The nomological net in the literature on ethics, integrity, and values as aspects of ethical leadership provided the following frameworks with which to view and interpret the topic including; social exchange theory, social learning theory, and open systems organizational learning theory. Though an individual's values were shown to have an indirect effect on one's personal choice of behaviors and outcomes, research on the relationships between ethical leadership, social exchange theory, and employee commitment revealed an administrator's direct interaction effects on employee outcomes such as OCB, trust, collective efficacy, and school outcomes (Tarter \& Hoy, 2004; Hansen, Bradley, Brown, Jackson, \& Dunford, 2013).

Further, the CCTC Standards, CPSEL 5: Ethics and Integrity provides recommendations that principals reflect on their values, use ethical behaviors, and demonstrate organizational citizenship behaviors to influence their school culture.

\subsubsection{Variables of Ethical Leadership}

The variables quantified in the GIEL scale have been shown to compare favorably with those in the literature that were malleable to administrator influence and related to improved school outcomes. School administrators can benefit from understanding the complex variables of the administrator's ethical leadership on the organization through the use of the GIEL tool that provides research-based data for reflection and planning (Dweck, 2010; Hansen et al., 2013; Lawton \& Páez, 2014). Operationalized items on the GIEL scale included seven factors found in the CPSEL Standard 5 and in the research literature on measurement of ethical leadership (Kearney, 2007).

The GIEL uses ethical leadership behaviors as the operationalized constructs for rating compared to the attitudinal dispositions of candidates. Though prior scales required by administrator candidates included self-rating of dispositions, research suggested that trait-based assessment have inherent biases and implicitly suggest a permanence, or fixedness, as enduring characteristics that works against a belief in growth through effort (Dweck, 1986; Hanson, 2015). This is of significant importance to agencies conducting program evaluation and accreditation of university programs under the auspices of the National Council for Teacher of Teacher Education (NCATE), the Council for the Accreditation of Educator Preparation (CAEP), and the California Commission on Teacher Credentialing (CCTC).

\subsubsection{Outcomes of Ethical Leadership}

Outcomes noted in the literature from the leaders' use of ethical behaviors included employee commitment to the leader, openness to share work related problems, perceptions of effective leaders by the followers, accomplishing ethical organizational goals, development of new ethical leaders, collective efficacy, and organizational citizenship behaviors. Results of the use of ethical behaviors also include professional growth and follower support for 
transformations of one's workplace or school culture leading to improved organizational outcomes (Sadeghifar et al., 2014; Tarter \& Hoy, 2004; Tschannen-Moran, 2003).

\subsubsection{Differences between GIEL and Previous Scales}

The GIEL scale includes a variety of features that differ and are considered an improvement from previous ethical leadership measurement scales. The GIEL scale quantifies ratings from participants about frequency of observed leader behaviors from a variety of raters including; the leader, followers, supervisors, and other stakeholders. The leader using the scale has a means to develop an understanding of the context in which he works. A comparison and contrast of self and others' perceptions provides a data-based source for beginning useful dialogues for understanding contextual differences in values and beliefs.

A recommended use of the GIEL includes collecting pre and post ratings, allowing for a means to reflect, set goals, and subsequently assess progress toward one's ethical leadership goals. This contributes to a cycle of continuous improvement, provides quantified, and research-based, data as artifacts evidencing attainment of expectations and competencies set as standards for ethical leaders (Brown et al., 2005; Collinson \& Cook, 2007; Kalshoven et al., 2010; Lawton \& Páez, 2014; Marzano et al., 2005; Reed et al., 2011; Sergiovanni, 2009).

\section{Methods}

This quantitative pilot-study empirically tested the factor structure and reliability of the newly developed Likert-style Graphical Inventory of Ethical Leadership (GIEL) scale, for quantifying key concepts, as behaviors, related to ethical leadership. Correlations and exploratory factor analyses were performed using pre-existing data as self-reports from a sample including 103 graduate students in an administrator preparation program at a private university located in a large southwestern state of the U.S.

\subsection{Data Sources and Participants}

The Likert-style GIEL survey instrument was provided online at www.gisasolutions.org to administrator candidates and to other participants in 360-degree evaluations; for the purpose of developing goals and strategies for growth to meet the expectations of Standard 5: Ethics and Integrity of the CPSEL. Responses $(n=103)$ were collected during the fall semester of the 2016/2017 school year. Respondents were graduate students in an administrator preparation program at a private university located in a large southwestern state of the U.S. The data used in the calculations for this pilot study was scrubbed of all identifying participant information and was held anonymous and confidential. Data will be destroyed after completion of the study.

\subsection{Instrumentation}

The survey items on the GIEL scale represent constructs of effective school leadership behaviors drawn from an extensive review of the literature on the measurement and identification of ethical leadership qualities. The scale items were reviewed by a panel of experts, including 12 active and retired public school administrators, 6 male and 6 female, with an average of 23 years' experience in the field. Six of the expert panel reviewers had 
earned doctorates and six had attained the master's degree level. The demographics for race included self-reports of four Hispanic/Latino, seven Caucasian, and one Filipino. The panel reviewed the 35 items for relevance, clarity, and comprehensiveness related to their effectiveness to communicate the qualities of ethical leadership behaviors to the survey participants and breadth and comprehensiveness of the concept.

The 35-items were purported to operationalize seven factors (5 items each); professional development, personal development, justice and fairness, communication, ethical decision-making, transformational leadership, and role model. Respondents reported frequencies of observed administrator behaviors by providing ratings for survey items on a Likert-style scale ranging from $0=$ behavior not evidenced; $1=$ behavior occasionally evidenced; 2 = behavior occurs frequently.

\subsection{Indices Used for Analyzing the Data}

This pilot study empirically tested the scale reliabilities using the predetermined indicator of Cronbach's alpha $>.60$ as an acceptable level for internal reliability of a scale in a pilot study; taking into account the number of items on the scale and the construct validity (Loewenthal, 2004). A variety of studies have been performed, and reported in the literature, demonstrating validity of the operationalized constructs on the GIEL scale (CCTC, 2014). The scale has strong face validity, currently being used in the administrator preparation program with administrator candidates. This study exceeded the preset indices of 100 surveys as a minimum number considered acceptable for a pilot study $(n=103)$. The preset indices for the ratio of number of survey respondents to final survey items will be approximately 5:1 (Tabachnick \& Fidell, 2001).

Issues related to normality of the data is not considered relevant when the sample size is sufficiently large ( $>30$ or 40 ) and an assumption of normality would not preclude the use of parametric procedures (Ghasemi \& Zahediasl, 2012, p. 487). For this study acceptable indices for skewness will be considered between \pm 2 and Kurtosis between \pm 7 (Hair, Black, Babin, \& Anderson, 2010; Bryne, 1998). Normality of the data would be reviewed visually, residuals checked for less than $20 \%$, and anti-image correlations > .5 (Fabrigar, Wegener, MacCallum, \& Strahan, 1999; Tabachnick \& Fidell, 2001).

\section{Results}

Data analyses included statistical tests using SPSS, Version 23 statistical software (IBM, 2015) to determine if the data fit a normal distribution and was considered reasonable for parametric analyses. All survey items were negatively skewed and this is considered normal respondent bias for self-report surveys using psycho-social factors (Trochim \& Donnelly, 2006; Field, 2000, 2009; Gravetter \& Wallnau, 2014). A review of the residuals revealed < $20 \%$ of the items had residuals $>.50(14 \%)$ therefore the next step in the analysis was to evaluate the significance of the Chi-squared calculation. The indices for rejecting the null of good fit was $\mathrm{p}<.001$. The Approximate Chi-square $=152.087, d f=101, p<.001$. Therefore the null was rejected and the data considered sufficiently correlated and further analyses could proceed (Mulaik, James, Van Alstine, Bennett, Lind, \& Stilwell, 1989; Field, 2000, 
2009).

\subsection{Correlations}

A bivariate correlation analysis was performed and significant relationships were found. However, results for the Bartlett's Test of Sphericity was found to be significant indicating that the items, although correlated, were not correlated so highly as to produce an identity matrix preventing the factor analysis from successfully reducing the data into interpretable factors. This was consistent based upon their item descriptions and the theory. An exploratory factor analysis was performed using SPSS, maximum likelihood extraction, and oblique rotation methods. Various EFA extraction methods were tried and yielded multiple pattern loadings and many factors (approximately 10), though most with too few items to be considered true factors. Indices for good factors included frequencies of item loadings, per factor, $(\geq 3)$, magnitude of loadings on the factor $(\geq .32)$, and low frequencies and low value loadings of the item on each of the other factors (minimal cross-loadings for a simple factor structure) (Gravetter \& Wallnau, 2014; Field, 2000 \& 2009; Brown, 2009; Albright \& Park, 2009).

\subsection{Principal Components Analysis}

The most parsimonious results were found forcing three factors using principal components analysis and direct oblimin rotation in an effort to retain the maximum amount of original variance while keeping the number of variables to a minimum (Conway \& Huffcutt, 2003). A review of the grouping of items descriptions and a comparison with the literature, revealed common themes among the factors and the factors were named.

Internal scale reliability ratings were above preset indices of .60 for pilot studies of measurement scales (Loewenthal, 2004). Each of the three scales consisted of at least three items, exhibited factor loadings $<.80$ and $>.30$ and had items that were minimally cross-loaded with items in other factors (Brown, 2009; Field, 2009; Gravetter \& Wallnau, 2014). Discriminant validity between scales was shown by items loading together above .3 on the factor and no cross-loadings. Table 1 shows the results of the PCA.

Table 1. Individual item factor loadings, significance, percentage of variance, and eigenvalues for items on the GIEL scale

\begin{tabular}{|l|l|l|l|l|l|}
\hline \multirow{2}{*}{ Items } & \multicolumn{3}{|c|}{ Scales } & & \multirow{2}{|c|}{} \\
\cline { 2 - 6 } & $\begin{array}{l}\text { Justice \& } \\
\text { Equitable } \\
\text { Decision-making } \\
\text { (JED) }\end{array}$ & $\begin{array}{l}\text { Communication } \\
\text { \& Modeling } \\
\text { (CM) }\end{array}$ & $\begin{array}{l}\text { Personal \& } \\
\text { Professional } \\
\text { Develop-ment } \\
\text { (PPD) }\end{array}$ & $M$ & SD \\
\hline $\begin{array}{l}\text { 12. Works to meet the unique needs } \\
\text { of those in the organization }\end{array}$ & $\mathbf{. 7 9 0}$ & -.276 & -.043 & 1.91 & .284 \\
\hline $\begin{array}{l}\text { 11. Truthful in communication with } \\
\text { others while respecting }\end{array}$ & $\mathbf{. 7 4 3}$ & -.169 & -.036 & 1.91 & .284 \\
\hline
\end{tabular}




\begin{tabular}{|c|c|c|c|c|c|}
\hline confidentiality & & & & & \\
\hline $\begin{array}{l}\text { 5. Seeks out new opportunities to } \\
\text { learn }\end{array}$ & .738 & -.011 & .087 & 1.82 & .414 \\
\hline $\begin{array}{l}\text { 19. Demonstrates proficiency in } \\
\text { multiple forms of communication } \\
\text { including, written, oral, } \\
\text { interpersonal, etc. }\end{array}$ & .738 & .291 & -.061 & 1.86 & .344 \\
\hline $\begin{array}{l}\text { 23. Demonstrates the ability to } \\
\text { prioritize decisions based on need }\end{array}$ & .629 & .135 & .180 & 1.87 & .334 \\
\hline $\begin{array}{l}\text { 18. Shares rationale for why } \\
\text { decisions are made }\end{array}$ & .593 & .039 & -.031 & 1.84 & .364 \\
\hline $\begin{array}{l}\text { 15. Seeks to understand those who } \\
\text { are different from them }\end{array}$ & .549 & .128 & .010 & 1.86 & .344 \\
\hline 31. Walks the Talk & .534 & .191 & .225 & 1.83 & .406 \\
\hline 4. Networks with colleagues & .503 & .210 & .065 & 1.15 & .746 \\
\hline 34. Personable and likable & .154 & .700 & -.066 & 1.91 & .316 \\
\hline $\begin{array}{l}\text { 16. Facilitates ongoing two way } \\
\text { internal external communication } \\
\text { among the entire school community }\end{array}$ & .090 & .648 & .133 & 1.81 & .397 \\
\hline $\begin{array}{l}\text { 20. Demonstrates active listening } \\
\text { skills }\end{array}$ & .111 & .639 & -.180 & 1.89 & .340 \\
\hline 35. Positive even when under stress & -.104 & .639 & -.005 & 1.82 & .390 \\
\hline 33. Models servant leadership & -.024 & .548 & .178 & 1.82 & .390 \\
\hline $\begin{array}{l}\text { 26. Creates a sense that we are all a } \\
\text { team }\end{array}$ & .006 & .532 & -.038 & 1.92 & .269 \\
\hline $\begin{array}{l}\text { 7. Recreational time and activities } \\
\text { with family, friends, church and } \\
\text { community members }\end{array}$ & -.156 & .010 & .743 & 1.68 & .546 \\
\hline $\begin{array}{l}\text { 8. Spending time reflecting and } \\
\text { thinking about important aspects of } \\
\text { their life }\end{array}$ & .003 & -.037 & .691 & 1.59 & .601 \\
\hline $\begin{array}{l}\text { 10. Deliberately explore community } \\
\text { events with diverse populations } \\
\text { other than one's own }\end{array}$ & -.016 & .242 & .686 & 1.33 & .706 \\
\hline $\begin{array}{l}\text { 9. Involvement with faith } \\
\text { community }\end{array}$ & .054 & -.071 & .682 & 1.15 & 756 \\
\hline $\begin{array}{l}\text { 2. Is a member of professional } \\
\text { organizations }\end{array}$ & .151 & .068 & .459 & 1.53 & .725 \\
\hline 1 Goes to Conferences & .094 & -.127 & .350 & 1.72 & .567 \\
\hline Percent of Variance & 25.746 & 10.336 & 9.159 & & \\
\hline Eigenvalue & 5.407 & 2.171 & 1.923 & & \\
\hline Cronbach alpha & .850 & .717 & .816 & & \\
\hline
\end{tabular}




\subsection{Three Factor Model}

\subsubsection{Justice and Equitable Decision-Making (JED)}

The first factor to emerge was a combination of mostly Justice \& Fairness and Decision-making variables. The factor was comprised of items $4,5,11,12,15,18,19,23 \&$ 31 and contributed $26 \%$ of the total variance explained by the three factor model. The items comprising this factor all related to ethical behaviors of supportive (12), truthful (11), communicative (19), open (5), understanding (15), interpersonal (19), and fair (4). Two items included wording related to decision-making (18 \& 23). A reveiw of the items warranted a combined name of JED. Cronbah's alpha was .850 showing good reliability.

\subsubsection{Communiction \& Modeling (CM)}

The second factor combined mostly from two varialbes of Role Modeling and Communication capturing items $16,20,26,33,34 \& 35$ and contributed to $10.4 \%$ of the total variance. The items included in this factor related to interpersonal skills of communication (16), listening (34), positive and likeable (34 \& 35), and modeling (33). One item from Transformational Leadership was also loaded on this factor, "creates a sense we are all a team" (26). The name, communicaiton \& modeling, was given that combines the two major categories of variables that combined to form this factor. Cronbach's alpha for this factor was .772 and could be improved, although is considered acceptable in a pilot study.

\subsubsection{Personal and Professional Development (PPD)}

The third factor was also a combination of two variables, Personal and Professional Development, including items $1 \& 2$, and 7-10 and contributed approximately $9.2 \%$ of the total variance explained by the three-factor model. The items were related to individual (7-10) and professional $(1 \& 2)$ development. Cronbach's alpha for this factor was .816 .

\subsection{Cross-Tabs}

Statistical analysis was not performed to explore the interdependence of the demographic data variables and to identify statistically significant differences $(p<.05)$ as demographic information was not collected.

\subsection{Multi-Collinearity}

Bartlett's Test of Sphericity determinant was $p<.0001$. Bartlett's tests the hypothesis that the correlation matrix of the data is an identity matrix. The Bartlett's test revealed issues could result in interpretation of the factors due to multicollinearity. Further analysis showed regression correlations between two factors within the normal limits of .32 to .80 (Cohen \& Cohen, 2002). Collinearity statistics tolerance should be $>0.1$ (or VIF $<10$ ) for all variables (Field, 2009). Results of regression on the IVs to test the assumption of collinearity indicated that multicollinearity was not a concern (GIEL Factors Mean Scores, Tolerance $=.87$, VIF $=$ 1.12). Therefore the factors could be considered unique items with individual contributions to the overall concept of ethical leadership. Figure 3 shows a model of the three-factor result of the principal component analysis 


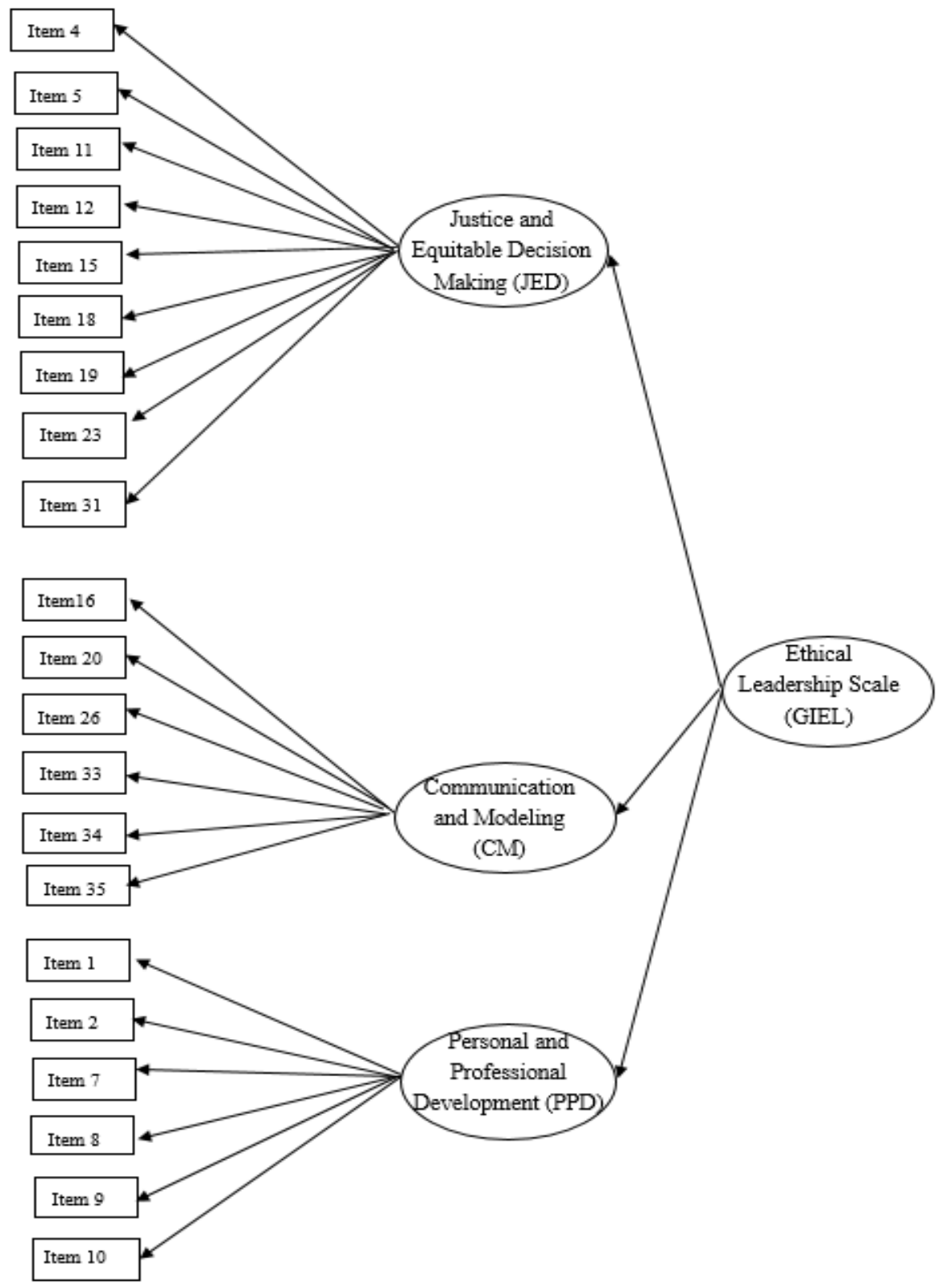

Figure 3. Proposed three-factor model of the Graphical Inventory of Ethical Leadership (GIEL)

\subsection{Multiple Regression Analysis}

A multiple regression analysis was run using JED as the independent variable and CM and PPD as the dependent variable to determine the level of relationship between the variables. The results from the multiple regression analysis revealed the IVs explained a significant proportion $\left(R^{2}=.263\right)$ of the variance in Justice and Equitable Decision-making $\left(F_{(2,102)}=\right.$ $17.870, p<.001)$. The strongest predictor was personal and professional development $(\beta$ $=.365)$, followed by communication and modeling $(\beta=.303)$. Table 2 shows $\beta$ and $\mathrm{p}$ values for the independent variables on JED. 
Table 2. Regression results on the factor justice \& equitable decision-making showing $\beta$ and $p$ values

\begin{tabular}{|l|l|l|c|}
\hline $\begin{array}{l}\text { Variables from the literature considered to explain } \\
\text { variations in Justice and Equitable Decision-making }\end{array}$ & $B$ & $\beta$ & $p$ \\
\hline Communication and Modeling & .324 & $.303^{* *}$ & $=.001$ \\
\hline Personal and Professional Development & .230 & $.365^{* *}$ & $<.001$ \\
\hline
\end{tabular}

Note. $R=.513$ and adjusted $R^{2}=.263^{* *}, d f=2, n=102 ; F=17.870$.

\section{Discussion of the Results}

A brief discussion follows explaining the theoretical support of the three factor model and why separate factors might combine as one to represent key behaviors of ethical leaders.

\subsection{Justice and Equitable Decision-Making}

A review of Figure 2 - Map of comparable and contrasting concepts with ethical leadership constructs, reveals the literature supports the combining of ethical values with decision-making. Kohlberg's (1958) Theory of the Stages of Moral Development as well as Rest's Four Stages Component Model (1999) establish a relationship between the concepts of justice and equitable decision-making. For example, Rest identified four psychological components contributing to moral maturity including, sensitivity, judgment, motivation, and character. He implies that an awareness and sensitivity of values, such as justice and equity, are a precursor to putting moral judgement into action through ethical or equitable decision-making. Schwartz (1992), an eminent social researcher wrote, "Values are criteria rather than qualities inherent in objects" (p. 1). That is, individuals use a hierarchy of beliefs, or ordering of important beliefs, when evaluating self or others, for making choices, and for setting goals.

\subsection{Communication and Modeling}

Theorists in the field of education, such as Dewey (1938/1997), and Vygotsky (1962), advanced the idea that the social environment and the individual influenced each other in a reciprocal process of learning. Bandura's (2001) social cognitive theory described a triadic model of learning including human cognition, one's environment, and the influence of social modeling on the behavior of the learner. Bandura explained, "... human functioning is rooted in social systems" (p. 15). Communication and modeling fall under a common theme of interpersonal skills related to relationship, feedback, and social influence.

\subsection{Personal and Professional Development}

Personal development is closely aligned with professional development when the concept of autonomous learning is considered. Personal choice to engage new experiences that challenge one's prior learning is fundamental to professional development. Chirkov, Ryan, Kim, and Kaplan (2003) in Hanson (2017) wrote, 
A person's sense of autonomy and control develops from experiencing a supportive social environment leading to positive experiences of individual development. Autonomy differs from independent action in that autonomous action involves an alignment with the values embedded in the actions undertaken. An autonomous person takes initiative, feels an intrinsic sense of control, and feels the tasks performed have relevance to him (p. 37).

\subsection{Items Removed from the Analysis}

Eleven of the 35 items on the scale were removed from the analysis for the following reasons: Items $14,17,32 \& 24$ showed kurtosis exceeding \pm 7 and were removed. Eight items $(13,21$, $22,24,27,29 \& 30$ ) crossloaded and were double-barreled, containing the word and. Double-barreled items suggest that the loadings are not stable and could vary depending upon the weight the rater gives to either part of the sentence. For example item 24 reads, "Incorporates the use of data and research when formulating decisions." The rater might focus on the use of data and consider research not part of the observed behaviors of the leader. Therefore this might load with decision making. However, if the rater focused on the research part of the item and did not observe the leader using data in decision making the item might load with professional development. Items 3, 6, 25 \& 28 included wording related to "professional readings ... outside of work ... shared leadership ... and shared vision ..." These items cross-loaded on two factors.

\section{Summary and Conclusion}

This paper provided a discussion of the GIEL scale developed by the master's department of educational leadership program at the subject university through the use of a SoTL research design.

\subsection{Research Question \#1}

The first research question of this study, "Is there a relationship between the individual factors included on the GIEL survey instrument?" was answered by correlation and regression analysis. All three scale factors significantly correlated though not so highly they were considered multi-collinear.

\subsection{Research Question \#2}

The study results answered question \#2, "Are the scale reliability indices of the GIEL instrument within predetermined acceptable parameters?" All three of the GIEL scales had internal reliability above the predetermined indices of $>.6$ for a pilot study. The scales can be considered reliable and to provide consistently accurate measurements of the participants' ratings of observed administrator ethical behaviors.

\subsection{Conclusion}

The results of this quantitative survey validation study suggest the use of the GIEL instrument provides reliable data to draw valid conclusions and for setting growth goals toward meeting Standard 5: Ethics and Integrity. The scale may be used to improve a leader's understanding of the construct of ethical leadership and, with repeated use over time, as an artifact to 
demonstrate growth. The GIEL survey operationalizes ethical leadership behaviors and can be used as a data source providing evidence of administrator, follower, supervisors, and stakeholder's perceptions of their leader in this area. When leaders develop ethical behaviors their followers perceive increased procedural justice and develop trust, leading to improved OCB and collective efficacy. Improved cultures lead to improved organizational outcomes and employee well-being (Hanson, Ruff, \& Bangert, 2016).

\subsection{Limitations}

Human-subject survey research may contribute to reporter bias resulting in a more positive self-report rating (Hoskin, 2012). The subsequent effect could provide a left-hand skew to the data, which was seen in this study. Onsite observations were not performed to confirm the validity of faculty and administrator self-reports regarding their perceptions of a leader's behaviors in their school context. This study had a limited pool of participants in an urban area in a large southwestern state. The results may not generalize to a different populations.

\subsection{Implications}

Implications of the results of this study suggest administrator candidates can compare their overall results from a pre assessment GIEL survey to the post assessment to determine growth on CPSEL Standard 5: Ethics and Integrity. If an administrator's growth plan is developed from sound data and reflection, then growth is more likely to occur. Additionally, a valid and reliable scale can provide research-based evidence of competencies on the CPSEL Standard 5 that support university recommendations for clearing administrator credentials in CASC programs. Data collected on the GIEL will provide opportunities for beginning dialogues with administrators, their faculty, school board members, and stakeholders regarding their perceptions of the administrator's behavior on the culture in their school. There are many implications for using research-based data from scales such as the GIEL for quantifying administrator ethics and integrity behaviors. Survey research is just a beginning to finding realistic ways to implement growth in a candidate or practicing leader (Netemeyer, Bearden, \& Sharma, 2003).

Administrators in schools and industry can provide the research-based evidence from the GIEL scale for developing a growth plan, reassess to determine growth, and for demonstrating competencies in ethical leadership behavior standards of expectations for the accountability agencies. Leaders can work to develop the three factors of ethical leadership such as being a role model, developing two-way communication channels, considering the effect on others when making decisions, participating in personal development activities, facilitating a shared vision using transformational leadership, participating in targeted professional development, and promoting justice and fairness that leads to organizational citizenship behaviors and positive employee outcomes in schools (Hoy, Tarter, \& Kottkamp, 1991; Kearney, 2007; Sanders \& Sheldon, 2009; Sadeghifar et al., 2014).

School districts can use the GIEL instrument and consider the logic and theory underlying the development of the instrument to plan professional development for administrators in their districts. University administrator preparation programs may include the GIEL instrument in 
their candidate screening process, for developing coursework, and provide the GIEL to candidates for personal and professional reflection. Other potential uses of the GIEL graphic organizer include; as a measure for school district administrator hiring/screening processes and as part of a 360-degree survey tool.

\subsection{Recommendations for Further Research}

Recommendations include expanding the Likert scale to a range of five: $1=$ never, $2=$ occasionally, 3 = frequently, $4=$ almost always, and $5=$ always; testing the instrument on a stratified random samples from diverse school contexts and populations to determine measurement reliability and generalizability; compare ethical leadership constructs with constructs from other validated instruments, such as the Transformational Leadership scale, Ethical Leadership at Work scale, Executive Servant Leadership scale (Kalshoven et al., 2011; Reed et al., 2011), Organizational Citizenship Behavior Questionnaire (Spector, Bauer, \& Fox, 2010), Collective Efficacy Scale (Goddard, 2002), What's My School Mindset? Scale (Mindset Works, Inc., 2015), and others. Further corrections to the items can be made based upon feedback from the expert panel review; correcting all double-barreled items retesting the transformational leadership factor; and adding more items to the communication \& modeling factor to raise the reliability of this factor.

\section{References}

Acton, E. D. D. (2016). Lord Acton quote library. Acton Institute for the Study of Religion and Liberty. Retrieved from http://www.acton.org/research/lord-acton-quote-archive

Albright, J. J., \& Park, H. M. (2009). Confirmatory factor analysis using Amos, LISREL, Mplus, and SAS/STAT CALIS. The Trustees of Indiana University, 1, 1-85.

Aristotle. (1947). In W. D. Ross (Trans.), Nicomachean ethics. New York: Random House.

Bandura, A. (1986). Social foundations of thought and action: A social cognitive theory. Englewood Cliffs, N.J.: Prentice-Hall.

Bandura, A. (2001). Social cognitive theory: An agentic perspective. Annual Review of Psychology, 52, 1-26. https://doi.org/10.1146/annurev.psych.52.1.1

Boomer, L. G. (2014). Leadership, Management and Administration. Linkedin. Retrieved January 16, 2017, from https://www.linkedin.com/pulse/20140425142012-6864846-careercurveballs-leadership-management-and-administration

Brown, J. D. (2009). Choosing the right type of rotation in pca and efa. Shiken. JALT Testing \& Evaluation SIG Newsletter, 13(3), 20-25. Retrieved from http://jalt.org/test/PDF/ Brown31.pdf

Brown, M. E., Treviño, L. K., \& Harrison, D. A. (2005). Ethical leadership: A social learning perspective for construct development and testing. Organizational Behavior and Human Decision Processes, 97(2), 117-134. http://dx.doi.org/10.1016/j.obhdp.2005.03.002

Brown, T. A. (2015). Confirmatory factor analysis for applied research (2nd ed.). New York: 
Guilford Press.

Byrne, B. M. (1998). Structural equation modeling with lisrel, prelis and simplis: Basic concepts, applications and programming. Mahwah, NJ: Erlbaum.

California Commission on Teacher Credentialing (CCTC). (2014). California professional standards for education leaders: Ensuring educator excellence (CPSEL). Retrieved May 7, 2016, from http://www.ctc.ca.gov/educator-prep/standards/cpsel-booklet-2014.pdf

California State University (CSU). (2015). Course redesign with technology. Retrieved from http://courseredesign.csuprojects.org/wp/sotl/

Cohen, P., \& Cohen, J. (2002). Applied Multiple Regression/Correlation Analysis for the Behavioral Sciences (3rd ed., p. 736). Routledge.

Collinson, V., \& Cook, T. (2007). Organizational learning improving learning, teaching, and leading in school systems. Thousand Oaks: Sage Publications.

Conway, J. M., \& Huffcutt, A. I. (2003). A review and evaluation of exploratory factor analysis practices in organizational research. Organizational Research Methods, 6, 147-168.

Dweck, C. (1986). Motivational processes affecting learning. American Psychologist, 41(10), 1040-1048. https://doi.org/10.1037/0003-066x.41.10.1040

Dweck, C. S. (2010). Mind-sets and equitable education. Principal Leadership, 10(5), 26-29. Retrieved from http://eschs.weebly.com/uploads/2/5/1/7/25174886/mind-sets-and-equitableeducation.pdf

Field, A. (2000). Discovering statistics using spss for windows. London-Thousand Oaks-New Delhi: Sage publications.

Field, A. (2009). Discovering statistics using SPSS. London: SAGE.

Gassler, G., Hug, T., \& Glahn, C. (2004). Integrated Micro Learning-An outline of the basic method and first results. Interactive Computer Aided Learning, 4, 1-7. Retrieved January 14, 2017, from file://C:/Users/jhanson/Downloads/Integrated_Micro_Learning-An_outline_of_ the_basic_pdf

Ghasemi, A., \& Zahediasl, S. (2012). Normality tests for statistical analysis: A guide for non-statisticians. International Journal of Endocrinology Metabolism, 10, 486-489. https://doi.org/10.5812/ijem.3505

Goddard, R. D. (2002). A theoretical and empirical analysis of the measurement of collective efficacy: The development of a short form. Educational and Psychological Measurement, 93, 467-476. https://doi.org/10.1177/0013164402062001007

Gravetter, F., \& Wallnau, L. (2014). Essentials of statistics for the behavioral sciences (8th ed.). Belmont, CA: Wadsworth.

Hair, J. F., Black, W. C., Babin, B. J., \& Anderson, R. E. (2010). Multivariate data analysis, a global perspective (7th ed.). New Jersey: Pearson Prentice Hall. 
Hansen, S. D., Alge, B. J., Brown, M. E., Jackson, C. L., \& Dunford, B. B. (2013). Ethical leadership: Assessing the value of a multifoci social exchange perspective. Journal of Business Ethics, 115, 435-449. https://doi.org/10.1007/s10551-012-1408-1

Hanson, J. (2017). Testing the difference between school level and academic mindset in the classroom: Implications for developing student psycho-social skills in secondary school classrooms. Journal of Educational Issues, 3(1), 44-63. http://dx.doi.org/10.5296/ jei.v3i1.10479

Hanson, J. L. (2015). Determination and validation of the "What's My School Mindset?" instrument factor structure (Order No. 3722197). Available from Dissertations \& Theses at Montana State University; ProQuest Dissertations \& Theses Global (1728126620).

Hanson, J., Ruff, W., \& Bangert, A. (2016). Exploring the relationship between school growth mindset and organizational learning variables: Implications for multicultural education. Journal of Educational Issues, 2(2), 222-243. http://dx.doi.org/10.5296/jei.v2i2.10075

Hoskin, R. (2012). The Dangers of Self-Report. Science Bravewaves. Retrieved from http://www.sciencebrainwaves.com/the-dangers-of-self-report/

Kalshoven, K., Den Hartog, D. N., \& De Hoogh, A. H. B. (2011). Ethical leadership at work questionnaire (ELW): Development and validation of a multidimensional measure. The Leadership Quarterly, 22(1), 51-69. https://doi.org/10.1016/j.leaqua.2010.12.007

Kearney, K. (2015). Moving leadership standards into everyday work: Descriptions of practice (2nd ed.). Sacramento, CA: WestEd.

Kearney, S. (2007). Principal influence: A study of its effect on school change. The University of Texas at San Antonio: ProQuest.

Kohlberg, L. (1971). From is' to 'ought': How to commit the naturalistic fallacy and get away with it in the study or moral development. In T. Mischel (Ed.), Cognitive development and epistemology (pp. 151-284). New York: Academic Press.

Kouzes, J. M., \& Posner, B. Z. (2007). Leadership challenge (4th ed., p. 22). San Francisco, CA: Jossey-Bass.

Lawton, A., \& Páez, I. (2014). Developing a framework for ethical leadership. Journal of Business Ethics, 130(3), 639-649. https://doi.org/10.1007/s10551-014-2244-2

LePine, J. A. (2002). The nature and dimensionality of organizational citizenship behavior: A critical review and meta-analysis. Journal of Applied Psychology, 87(1), 52-65. https://doi.org/10.1037/0021-9010.87.1.52

Loewenthal, K. M. (2004). An introduction to psychological tests and scales (2 ed.). Hove, UK: Psychology Press.

Loose, W., \& Marcos, T. (2015). iPrincipals: Innovative Themes, Strategies, and Recommendations of Ten Online University Educational Leadership Programs. Educational Leadership and Administration: Teaching and Program Development, 26. Retrieved from 
http://files.eric.ed.gov/fulltext/EJ1062272.pdf

Loose, W., \& Marcos, T. (2016). Instructional Design for Millennials: Instructor Efficiency in Streamlining Content, Assignments, and Assessments. Increasing Productivity and Efficiency in Online Teaching. IGI Global Disseminator of Knowledge. https://doi.org/10.4018/978-15225-0347-7.ch001

Marcos, T. A., \& Loose, W. V. (2014). iPrincipals: How a California university educational leadership program is preparing the next generation of school administrators online. Educational Leadership and Administration, 25, 92.

Marzano, R. J., Waters, T., \& McNulty, B. A. (2005). School leadership that works. Alexandria: ASCD.

Mindset Works, Inc. (2015). What's My School Mindset? (Para. 5). Retrieved October 26, 2016, from https://www.mindsetworks.com/assess/

Motowidlo, S. J., \& Schmit, M. J. (1999). Performance assessment in unique jobs. In D. R. Ilgen \& E. D. Pulakos (Eds.), The changing nature of performance (pp. 56-86). San Francisco: Jossey-Bass.

Motowidlo, S. J., Borman, W. C., \& Schmit, M. J. (1997). A theory of individual differences in task and contextual performance. Human Performance, 10, 71-83. http://dx.doi.org/10.1207/ s15327043hup1002_1

Mulaik, S. A., James, L. R., Van Alstine, J., Bennett, N., Lind, S., \& Stilwell, C. D. (1989). Evaluation of goodness-of-fit indices for structural equation models. Psychological Bulletin, 105(3), 430. https://doi.org/10.1037/0033-2909.105.3.430

Netemeyer, R. G., Bearden, W. O., \& Sharma, S. (2003). Scaling procedures: Issues and applications. Thousand Oaks: Sage Publications. https://doi.org/10.4135/9781412985772

Organ, D. W., \& Ryan, K. (1995). A meta-analytic review of attitudinal and dispositional predictors of organizational citizenship behavior. Personnel Psychology, 48(4), 775-802. https://doi.org/10.1111/j.1744-6570.1995.tb01781.x

Publius. (2016). Federalist papers no. 51 (1788). Bill of Rights Institute. Retrieved from http://billofrightsinstitute.org/founding-documents/primary-source-documents/the-federalistpapers/federalist-papers-no-51/

Reed, L. L., Vidaver-Cohen, D., \& Colwell, S. R. (2011). A new scale to measure executive servant leadership: Development, analysis, and implications for research. Journal of Business Ethics, 101(3), 415-434. https://doi.org/10.1007/s10551-010-0729-1

Rest, J. R., Narvaez, D., Bebeau, M., \& Thomas, S. J. (1999). Postconventional moral thinking: A neo-Kohlbergian approach. Mahweh, New Jersey: Lawrence Erlbaum Associates.

Sadeghifar, J., Ashrafnejad, F., Mousavi, S. M., Nasiri, A. B., Vasokolaei, G. R., Zadeh, K. Z., ... Mosavi, M. (2014). The relationship between organizational learning and staff empowerment in hospitals: A correlational study in Iran. Asian Social Science, 10(16), 27-33. 
https://doi.org/10.5539/ass.v10n16p27

Sanders, M., \& Sheldon, S. (2009). Principals matter: A guide to school, family, and community partnerships. Thousand Oaks, Calif.: Corwin.

Sergiovanni, T. J. (2009). The principalship: A reflective practice perspective. Boston: Pearson.

Spector, P. E., Bauer, J. A., \& Fox, S. (2010). Measurement artifacts in the assessment of counterproductive work behavior and organizational citizenship behavior: Do we know what we think we know? Journal of Applied Psychology, 95(4), 781-790. http://dx.doi.org/10.1037/a0019477

Tabachnick, B. G., \& Fidell, L. S. (2001). Using Multivariate Statistics. Boston: Allyn and Bacon.

Tarter, C., \& Hoy, W. (2004). A systems approach to quality in elementary schools: A theoretical and empirical analysis. Journal of Educational Administration, 42(5), 539-554. https://doi.org/10.1108/09578230410554052

Trochim, W. M., \& Donnelly, J. P. (2006). The research methods knowledge base (3rd ed.). Cincinnati, OH: Atomic Dog.

Trustees of Dartmouth College. (2106). Common rater errors. Human Resources. Retrieved from http://www.dartmouth.edu/ hrs/profldev/performance_management/rater_errors.html

Tschannen-Moran, M. (2003). Fostering organizational leadership: Transformational leadership and trust. In W. K. Hoy \& C. G. Miskel (Eds.), Studies in Leading and Organizing Schools (pp. 157-179). Information Age Publishing: Greenwich.

Weber, M. (1947). In A. M. Henderson \& T. Parsons (Trans.), The Theory of Social and Economic Organization. The Free Press and the Falcon's Bring Press.

Yukl, G., Mahsud, R., Hassan, S., \& Prussia, G. (2013). An improved measure of ethical leadership. Journal of Leadership and Organizational Studies, 20, 38-48. https://doi.org/10.1177/1548051811429352

\section{Copyright Disclaimer}

Copyright for this article is retained by the author(s), with first publication rights granted to the journal.

This is an open-access article distributed under the terms and conditions of the Creative Commons Attribution license (http://creativecommons.org/licenses/by/3.0/). 